\title{
PATRIMONIO CULTURAL, CIUDADES Y RENTABILIDAD
}

Guadalupe Margarita González Hernández

Unidad Académica de Estudios del Desarrollo, UAZ

En 2013, se cumplirán veinte años del nombramiento de Patrimonio Cultural de la Humanidad del Centro Histórico de la ciudad de Zacatecas otorgado por la Organización de las Naciones Unidas para la Educación, la Ciencia y la Cultura (UNESCO) y, se supone, será motivo de celebración entre las autoridades estatales, las organizaciones culturales y los zacatecanos en general. Este acontecimiento da motivos para la reflexión.

\section{L} a distinción de patrimonio mundial (World Heritage) tiene implicaciones más allá de pertenecer a un conjunto de bienes tangibles e intangibles que deben ser conservados para el disfrute, conocimiento y conservación de la civilización. La primera, refiere precisamente a la noción del nombramiento. La etiqueta de patrimonio mundial significa, de entrada, distinguir, diferenciar, clasificar y seleccionar ${ }^{1}$ lo que se considera valioso para la civilización. Independientemente de discutir para quién es valioso, cómo se determinó que era valioso y cuáles fueron los criterios para designarlo como valor, dicha distinción también significa exclusión. La etiqueta de patrimonio mundial, por consiguiente, segrega y excluye todos aquellos valores, significados, prácticas, bienes y espacios culturales que no cumplen con los requisitos establecidos por la UNESCO. Esta distinción orienta los flujos de capitales y turistas hacia los lugares portadores, dejando cualquier otro fuera de foco.

Segundo, la UNESCO, como organismo supranacional, crea, formula, consensa, establece y dicta cuáles son los lineamientos de lo que se considera no sólo patrimonio mundial, sino todo lo que tiene que ver con el desarrollo educativo, cultural y científico. En otras palabras, induce hacia dónde debe encaminarse la humanidad en su evolución como civilización. No obstante, la UNESCO representa intereses y, generalmente, son los dominantes, los hegemónicos. Es la clase capitalista la que determina valores simbólicos, criterios, significados de lo que debe ser considerado como bienes culturales tangibles e intangibles. ${ }^{2}$ La patrimonialización ayuda a legitimar cierto orden sociopolítico y marco conceptual ideológico. ${ }^{3}$ La patrimonialización, por tanto, induce al conflicto, al imponer intereses hegemónicos como universales a través de estrategias y agendas a los Estados nacionales y agentes involucrados con el fin de mantener, conservar y administrar dicho patrimonio. Y la UNESCO, a través del nombramiento, trasmite al resto de los grupos, la hegemonía de la clase dominante.

Tercero, el mantenimiento, conservación y administración del patrimonio mundial en un espacio específico coloca a los actores y agentes involucrados a competir por recursos humanos y financieros. Es decir, los proyectos de conservación y mantenimiento patrimonial estimulan el desarrollo económico de acuerdo con la liberación de acciones individuales y colectivas empresariales con base en los derechos en la propiedad privada, libre mercado y libre comercio. ${ }^{4}$ Los lugares patrimonio mundial (cultural, natural y mixto) ${ }^{5}$ se ven forzados a competir por la atracción de capitales y personas extranjeros con el fin de asegurar su ventaja locacional, su distinción, donde la gestión estatal juega el papel principal para la rentabilización del patrimonio por medio de negociaciones y disputas de poder con los actores involucrados.

Cuarto, a través de la planeación, gobernabilidad y gobernanza, las autoridades estatales crean proyectos de conservación y renovación que involucran principalmente a las ciudades. ${ }^{6}$ De los 936 patrimonios mundiales registrados en 2012, 725 son culturales, 183 naturales y 28 mixtos. México, el principal en América Latina, cuenta con 29 culturales (16 localizados en ciudades históricas) y 4 naturales de un total de 33 patrimonios mundiales. ${ }^{7}$ Las ciudades consideradas patrimonio cultural, por tanto, son objetivo de proyectos que involucran la asociación público-privada, donde el Estado (a través de las autoridades gubernamentales locales) se convierte en el facilitador respecto de los intereses estratégicos del desarrollo capitalista con el fin de atraer fuentes externas de financiamiento y nuevas fuentes de empleo. ${ }^{8}$

Quinto, los proyectos de mantenimiento y conservación patrimonial de las ciudades históricas se sustentan en la construcción especulativa del lugar. ${ }^{9}$ Dicha construcción significa crear un argumento que justifique la intervención por parte del capital y del Estado como el mecanismo único e idóneo para obtener beneficios para la población involucrada. Se abren los bienes culturales tangibles e intangibles a los capitales en sus formas diferentes de expresión (inmobiliario, comercial, turístico) con el discurso de crear empleos, mejorar el bienestar social y disminuir las desigualdades sociales. La mercantilización de prácticas, espacios y bienes induce a la apropiación de la clase dominante para establecer su hegemonía ${ }^{10}$ y reorganiza el sentido de la producción y significado de las prácticas urbanas. ${ }^{11}$

Sexto, a través de la inversión en innovación cultural (introducción de nuevos comportamientos y tendencias 
culturales), mejora física del ambiente urbano (mantenimiento de cascos históricos, aunque no se descarta el cambio a estilos modernos y posmodernos de arquitectura y diseño urbano) y el entretenimiento (organización de espectáculos temporales o permanentes), las ciudades históricas debe parecer lugares innovadores, estimulantes, creativos y seguros para quienes las viven y visitan, así como para quienes se quieren divertir o consumir. ${ }^{12}$

Séptimo, en un clima donde las políticas de restructuración económica neoliberales exigen las finanzas estatales sanas, el Estado, a través de la gestión e inversión en infraestructura física, social y cultural, y equipamiento urbano y la asociación público-privada de liberación del mercado inmobiliario, auspicia el riesgo, y el sector privado acapara los beneficios. ${ }^{13}$ No obstante, dicha asunción por parte del sector público es a nivel local, dejando sin responsabilidad y sin conflictos sociales a autoridades estatales y federales. ${ }^{14} \mathrm{El}$ capital, flexible ante los riesgos, puede abandonar el lugar cuando lo considere necesario o, más bien, cuando la rentabilidad se agote, sin importar la distinción adquirida.

Finalmente, la distinción es efímera y superficial. Las ciudades que ostentan la etiqueta en su intento por ofertar ambiente idóneo para capitales y turistas emulan y copian estrategias exitosas en otros espacios similares. La renta monopólica de la distinción se acaba en tanto que otro patrimonio cultural replica bienes, prácticas y eventos. ${ }^{15}$ Bajo el pretexto de facilitar el consumo, se les acostumbra a los usuarios a percibirlo como simple, fácil, sin conflictos, sin complejidad; se percibe "la realidad en un espejo aburrido, con tan pocos matices que al final lo real resulta menos atractivo que podría ser". ${ }^{16}$

Por ello, la etiqueta de Patrimonio Cultural Mundial, camufla un ambiente propicio a los negocios, por medio de la elaboración e implantación de estrategias para atraer capitales a las ciudades históricas. Esta estrategia (Patrimonio Cultural de la Humanidad), aunque no es única (existen las distinciones de "ciudades globales", "ciudades creativas", "ciudades tecnológicas", "ciudades turísticas"), ha sido de las más efectivas para atraer flujos financieros, de producción y de consumo de alta movilidad y flexibilidad para su espacio. ${ }^{17} \mathrm{Y}$ el carácter especulativo de las inversiones urbanas deriva de la incapacidad de prever exactamente si el proyecto de renovación y conservación urbana tendrá éxito o no, en un mundo donde la inestabilidad y volatilidad económica son la regla. ${ }^{18}$

El nombramiento de Patrimonio Cultural de la $\mathrm{Hu}-$ manidad no hace más que perpetuar el proceso de reproducción social del capital a través de la introducción de elementos culturales a la mercantilización ${ }^{19} \mathrm{y}$ del posicionamiento social ${ }^{20}$ de los grupos hegemónicos en contrapartida con la exclusión de prácticas, percepciones y actividad económica de estratos urbanos dominados. ${ }^{21}$
Referencias

${ }^{1}$ Bourdieu, Pierre (2003), La distinción. Criterio y bases sociales del gusto, México, Taurus.

${ }^{2}$ Troncoso, Claudia y Analía Almirón (2005), “Turismo y patrimonio. Hacia una relectura de sus relaciones" en Aportes y Transferencias, vol. 1, no. 9, pp. 56-74.

${ }^{3}$ Poria, Yaniv y Gregory Ashworth (2009), "Heritage TourismCurrent Resource for Conflict" en Annals of Tourism Research, vol. 36 , no. 3, pp. 522-525.

${ }^{4} \mathrm{Su}$, Xiaobo (2010), "Urban conservation in Lijiang, China: Power structure and funding systems" en Cities 27, pp. 164-171.

${ }^{5}$ UNESCO (2012), World Heritage List, en http://whc.unesco. org/en/list consultado 23/05/2012.

${ }^{6}$ González, Guadalupe y José González (2010), “Turismo, bienestar social, gobernabilidad: Centro Histórico de Zacatecas" en Bustamante, Carlos et al. (coords.), Situación actual del país: políticas públicas y desarrollo regional sustentable, México, AMECIDER, pp. 1-17.

${ }^{7}$ UNESCO (2012), op cit.

${ }^{8}$ Harvey, David (2011), Condição pós-moderna, Brasil, Edições Loyola; Hiernaux, Daniel (2005), "Imaginarios y lugares en la reconquista de los centros históricos" en Ciudades, no. 65, enero-marzo, pp. 15-21.

${ }^{9}$ Harvey, David (2006), A produção capitalista do espaço, Brasil, Annablume.

${ }^{10}$ García Canclini, Néstor (2002), Culturas populares en el capitalismo, México, Grijalbo.

${ }^{11}$ González, Guadalupe (2009), "La revitalización del Centro Histórico de Zacatecas y la conciencia social” en Economía, Sociedad y Territorio, vol. IX, no. 30, mayo-agosto, pp. 473-513.

${ }^{12}$ Harvey (2006), op cit.; Harvey (2011), op cit.; González (2009), op cit.

${ }^{13}$ Harvey (2006), op cit.; Harvey (2011), op cit.

${ }^{14}$ Harvey (2006), op cit.; González, Guadalupe (2012), “Imagen, satisfacción y viabilidad del proyecto turístico: Centro Histórico de Zacatecas, México" en García, Rodolfo y Francisco Contreras (coords.), Seminario Estatal de Universitarios: Por una nueva estrategia de desarrollo integral para Zacatecas, vol. II, México, Universidad Autónoma de Zacatecas.

${ }^{15}$ Harvey (2006), op cit.

${ }^{16}$ García (2002), op cit., p. 148.

${ }^{17}$ Amin, Ash (2008), "Collective culture and urban public space" en City, vol. 12, no. 1, Gran Bretaña, Routledge, pp. 5-24.

${ }^{18}$ Harvey (2006), op cit.

${ }^{19}$ García (2002), op cit.

${ }^{20}$ Bourdieu, Pierre (2003), Capital cultural, escuela y espacio social, México, Siglo XXI.

${ }^{21}$ Amin (2008), op cit. 